\title{
Assessment of nitric oxide (NO) potential to mitigate COVID-19 severity
}

\author{
Swati Srivastava1 (i) $\cdot$ Iti Garg $^{1} \cdot$ Anju A. Hembrom ${ }^{1} \cdot$ Bhuvnesh Kumar $^{1}$
}

Received: 8 February 2021/ Accepted: 20 May 2021/Published online: 3 June 2021

(C) Indian Virological Society 2021

\begin{abstract}
Novel coronavirus disease by SARS-CoV-2 virus (also known as COVID-19) has emerged as major health concern worldwide. While, there is no specific drugs for treating this infection till date, SARS-CoV-2 had spread to most countries around the globe. Nitric oxide (NO) gas serves as an important signaling molecule having vasodilatory effects as well as anti-microbial properties. Previous studies from the 2004 SARS-CoV infection demonstrated that NO may also help to reduce respiratory tract infection by inactivating viruses and inhibiting their replication cycle and is an effective supportive measure for treating infection in patients with pulmonary complications. NO gas inhalation is being suggested as potential therapy for managing severe acute respiratory distress syndrome in COVID-19 patients. In view of COVID-19 pandemic, several clinical trials are underway to examine the effects of NO inhalation on infected patients. Previously published reports on beneficial effects of endogenous $\mathrm{NO}$ and NO inhalation therapy were thoroughly searched to assess the potential of NO therapy for treating COVID-19 patients. Present report summarized the therapeutic importance of NO to reverse pulmonary hypertension, restore normal endothelial activity and produce antithrombotic effects. In addition to this, NO also reduces
\end{abstract}

Swati Srivastava and Iti Garg have contributed equally to this work.

Swati Srivastava

sri_swati@rediffmail.com

$\bowtie$ Iti Garg

itidipas@gmail.com

1 Genomics Group, Defence Institute of Physiology and Allied Science (DIPAS), Defence Research and Development organization (DRDO), Lucknow Road, Timarpur, Delhi 110054, India viral infection by inhibiting its replication and entry into the host cell. In absence of vaccine and effective treatment strategies, we suggest that NO inhalation therapy and NO releasing foods/compounds could be considered as an alternative measure to combat COVID-19 infection.

Keywords COVID-19 • Nitric oxide (NO) · vasodilation · hypertension

\section{Brief report}

Severe acute respiratory syndrome coronavirus (SARSCoV-2), also known as COVID-19, has emerged as a global pandemic in recent times. The virus causes flu like symptoms with high fever, cough and asthenia [24] and may progress to severe lung injury in some high-risk individuals such as the elderly people with weak immune system and individuals with other co-morbidities [6]. The infection is either asymptomatic or mild, with the most common symptoms being fever, headache, loss of smell and nasal obstruction in about $80-90 \%$ of cases and only around $10 \%$ of the infected patients have severe infection with dyspnoea, hypoxemia and extensive radiological involvement of the lung parenchyma. In extreme cases, this virus is likely to cause severe interstitial pneumonia, acute respiratory distress syndrome (ARDS) and subsequent multiorgan failure leading to respiratory failure and eventually death [18]. Thus, the symptoms vary from individual-to-individual ranging from asymptomatic infection to severe respiratory failure. Whereas, less than $5 \%$ of cases present critical condition, multi-organ failure and death $[9,25]$. The general symptoms of the patients remain in a state of mild upper respiratory tract disease for an extended period of 8-10 days, after which up to $42 \%$ individuals 
may develop ARDS and severe hypoxemia among which 61-81\% require urgent mechanical ventilation [7]. Currently, there are no designated drugs for COVID-19 infection treatment and even vaccine is yet to be developed. Most of the pharmacological treatment strategies being used are derived from experience gained during the SARS-CoV or MERS-CoV pandemics or from in vitro studies [5, 27]. Several potential molecules with antiviral, anti-inflammatory and immunomodulatory properties are under different stages of clinical trial for treatment of COVID-19 [7, 28].

Nitric oxide (NO) is a natural vasodilator produced by vascular endothelial cells. It acts as a signaling molecule between the cells and is also involved in wide range of processes [3]. NO is synthesized by three enzymes that catalyze the oxidation of 1 -arginine to $\mathrm{NO}$ and l-citrulline [3]; namely neuronal nitric oxide synthase (nNOS), endothelial NOS (eNOS), and inducible NOS (iNOS). Whereas, nNOS and eNOS are constitutively expressed in calcium dependent manner [19], iNOS is independent of calcium ion concentration and is expressed only in activated cells [4]. Up-regulation of iNOS has been commonly seen during infections, and its anti-microbial activities have been described for several bacteria and viruses [1, 19] and serves as a critical molecule for immune response against pathogens and infections. Nitric oxide has been proven as a powerful molecule playing a critical role in a broad array of biological functions. It targets a variety of microbes such as bacteria, fungi, helminths, protozoa and viruses. The mechanism of virus inactivation by NO involves inactivation of various modifying proteins and nucleic acids involved in virus replication cycle [26]. Higher levels of basal exhaled NO have been correlated with milder symptoms of common cold in humans previously [20]. Also, NO has been demonstrated to inhibit pulmonary viral replication in pigs [11].

Due to proven inhibitory effects of NO on viral infections, it is being investigated as a candidate for therapy against COVID-19. Akerstrom and co-workers demonstrated that NO generated by iNOS inhibits the SARS-CoV replication cycle. They further reported that organic NO donor compound, $S$-nitroso- $N$-acetylpenicillamine facilitates inhibition of SARS-CoV replication in a concentration dependent manner [29]. Lower NO levels in the airways may facilitate progression of SARS-CoV-2 infection. A recent study suggests prevention of COVID-19 infection by avoiding mouth breathing, as it bypasses filtering effect by nose and decreases NO levels in airways. Rather simpler devises that help in promoting nasal breathing during sleep may also prevent infections [15].

$\mathrm{NO}$ is produced at 10 parts per million (ppm) in the human sinuses and diffuses into bronchi and lungs to produce vasodilatory and broncho-dilatory effects [12]. It also contributes to activation of ciliary movement [21] and secretion of mucus [17], which in turn helps in prevention of viral particles entering respiratory tract. Several clinical trials are being conducted on effectiveness of NO inhalation therapy to prevent disease progression in patients with COVID-19. A clinical trial intervention to assess the lung diffusion capacity for $\mathrm{NO}$ and Carbon Monoxide (CO) early after mild-to-severe COVID-19 has completed the clinical trial phase, but the details of the study has not been published yet (Table 1). Most important clinical presentation of COVID-19 is acute respiratory distress in the lungs which later propagates to other vascular networks throughout the body. It is also associated with plateletendothelial dysfunction and abnormal thrombotic clots [16]. Since intact endothelium releases NO which produces vasodilator and anti-thrombotic effects [23], the prime cause for endothelial dysfunction and thrombotic events during COVID-19 infection is NO deficiency due to suppressed eNOS in injured vessels. Thus, restoration of NO levels may contribute to vasodilation, thus releasing pulmonary hypertension and create anti-thrombotic milieu. In addition, nitric oxide interferes with the interaction between viral S-protein of coronavirus and its receptor molecule in the host, angiotensin converting enzyme-2 (ACE-2). Thus, the critical step of infection, i.e., the viral entry into the host cell is affected by the presence of NO, as it mediates S-nitrosylation of viral cysteine proteases and host serine protease, TMPRSS2 [2, 10, 22]. Thus, NO inhalation may be beneficial in mitigating severity of COVID-19 infection in many different ways as summarized in Fig. 1.

The availability of nitric oxide in the human body depends on presence of NO donor compounds such as arginine, citrulline, nitroglycerin and phosphodiesterase inhibitors and consumption of NO releasing foods like green leafy vegetables, beetroot etc. [14, 13]. NO donors are a heterogeneous group of compounds which either release NO or an NO-related species. The type and extent of biological action of these compounds also depends on the form in which NO is released and amount of NO produced. The dietary inorganic nitrate releasing foods has been shown to be effective in restoring endothelial function, reducing pulmonary hypertension and inducing antimicrobial activity [8]. Thus, restoring levels of NO through dietary inorganic nitrate may prevent and even mitigate sever effects of COVID-19 infection. 


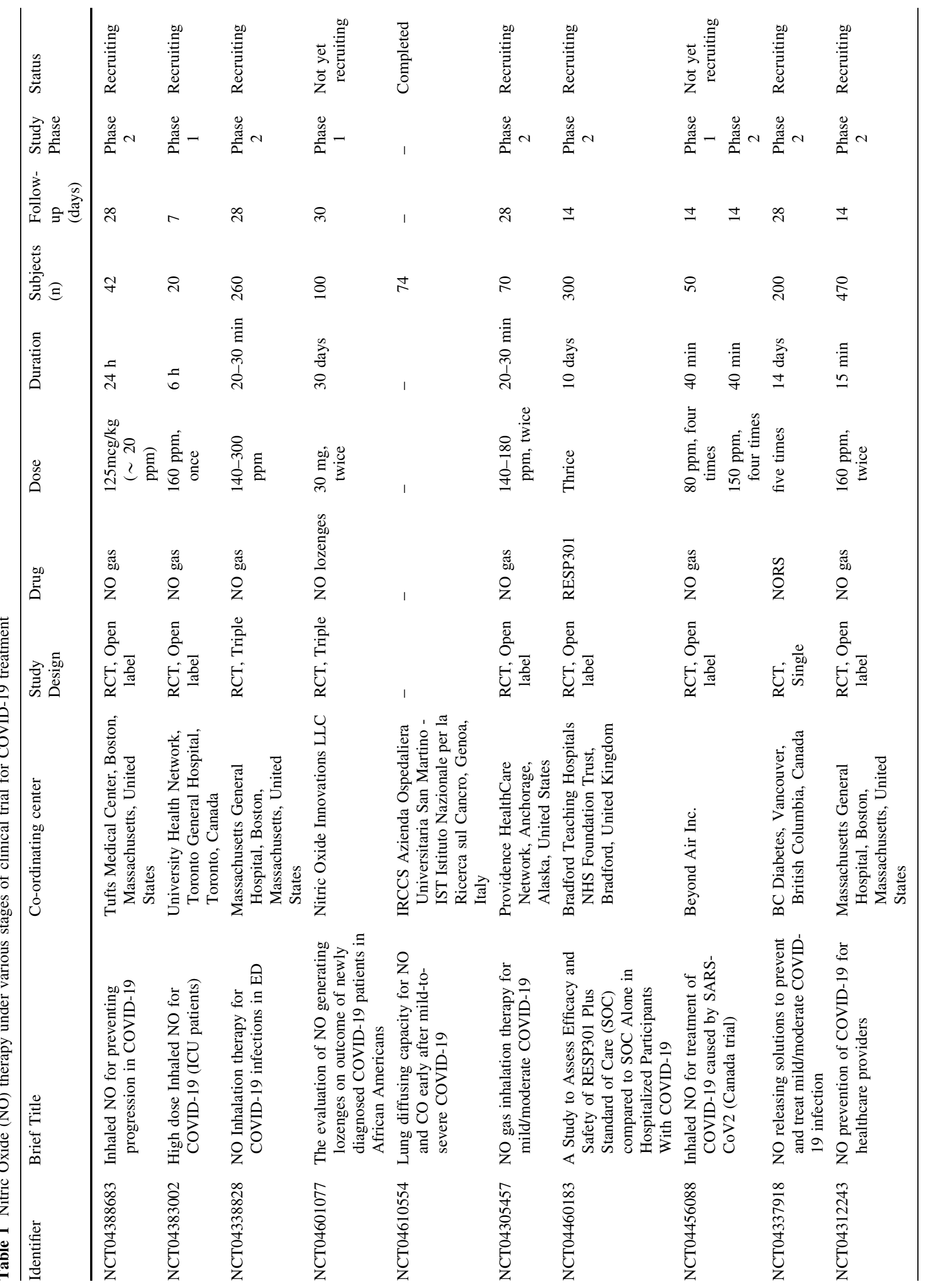




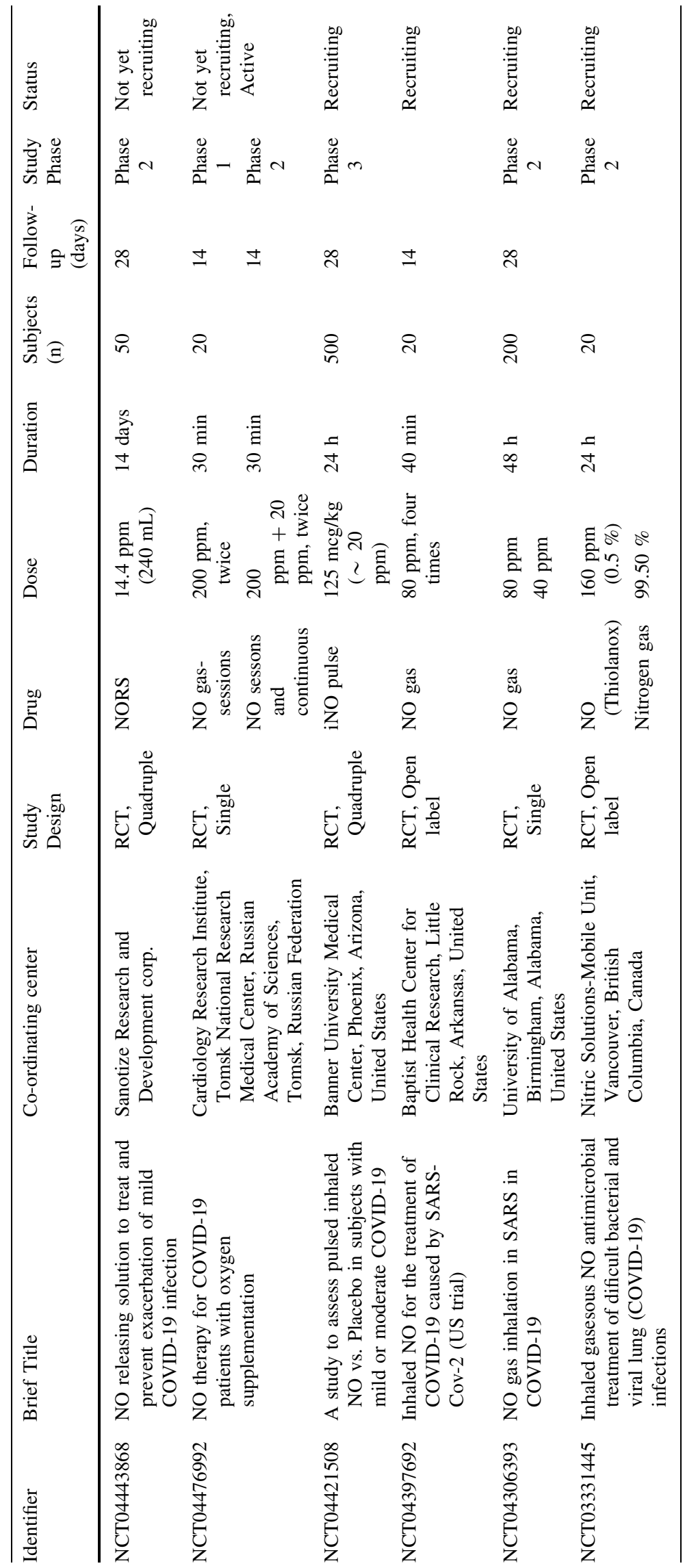


Fig. 1 Beneficial effects of NO inhalation therapy for inhibiting COVID-19 infection

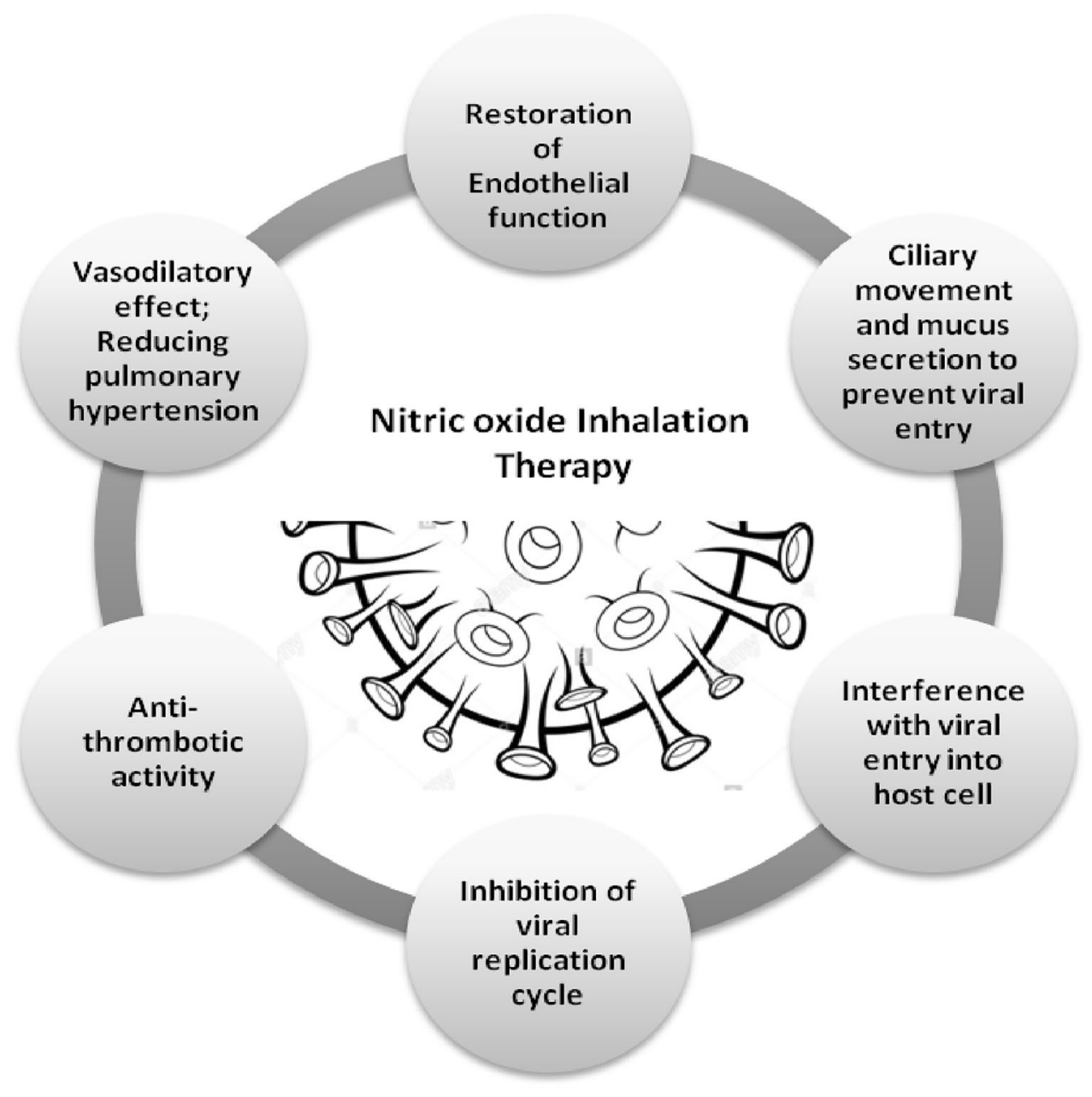

\section{Conclusions}

The studies described in this report suggest that mechanisms designed to increase NO levels via gas inhalation or dietary intake may improve oxygen supply to tissues and restore normal vessel functioning. Treatment with NO inhalation therapy may reverse pulmonary hypertension and improve severe hypoxic condition in patients of COVID-19.

Funding The authors have not received any funding for this work.

Availability of data and material: Not applicable.

Code availability Not applicable.

\section{Declarations}

Conflict of interest The authors have declared that no competing interests exist.

Ethics approval Not applicable.
Consent to participate Not applicable.

Consent for publication All authors have agreed for publication of this manuscript in its current form.

\section{References}

1. Adler H, Beland JL, Del-Pan NC, Kobzik L, Brewer JP, Martin TR, Rimm IJ. 1997. Suppression of herpes simplex virus type 1 (HSV-1)-induced pneumonia in mice by inhibition of inducible nitric oxide synthase (iNOS, NOS2). J Exp Med 1997;185:1533-1540.https://doi.org/10.1084/jem.185.9.1533.

2. Akerstrom S, Gunalan V, Keng CT, Tan Y-J, Mirazimi A. Dual effect of nitric oxide on SARS-CoV replication: viral RNA production and palmitoylation of the $\mathrm{S}$ protein are affected. Virology. 2009;395:1-9. https://doi.org/10.1016/j.virol.2009.09.007.

29. Akerström S, Mousavi, J, Klingström J, Leijon M, Lundkvist A, Mirazimi A. Nitric oxide inhibits the replication cycle of severe acute respiratory syndrome coronavirus. J Virol. 2005;79(3):1966-9. https://doi.org/10.1128/JVI.79.3.19661969.2005.

3. Boucher JL, Moali C, Tenu JP. Nitric oxide biosynthesis, nitric oxide synthase inhibitors and arginase competition for 1-arginine utilization. Cell Mol Life Sci. 1999;55:1015-28. https://doi.org/ $10.1007 / \mathrm{s} 000180050352$. 
4. Coleman JW. Nitric oxide in immunity and inflammation. Int. Immunopharmacol 2001; 1:1397-1406.

5. Dhama K, Khan S, Tiwari R, Sircar S, Bhat S, Malik YS, Singh KP, Chaicumpa W, Bonilla-Aldana DK, Rodriguez-Morales AJ. (2020). Coronavirus Disease 2019-COVID-19. Clin Microbiol Rev, 33(4), e00028-20; https://doi.org/10.1128/CMR.00028-20.

6. Garg I, Srivastava S, Rai C, Kumar V, Hembrom AA, Ghosh N, Kumari B, Bansal A, Kumar B. Coronavirus (covid-19): Prognostic risk associated with comorbidities and age. Int J Recent Sci Res. 2020;11(A):37983-6. https://doi.org/10.24327/ijrsr.2020. 1104.5218. Issue, 04 ).

7. Gibson PG, Qin L, Puah SH. . COVID-19 acute respiratory distress syndrome (ARDS): clinical features and differences from typical pre-COVID-19 ARDS. Med J Aust. 2020;213(2):54-6.https://doi.org/10.5694/mja2.50674.

8. Green SJ. Nitric oxide in mucosal immunity. Nat Med. 1995;1:515-7. https://doi.org/10.1038/nm0695-515.

9. He F, Deng Y, Li W. Coronavirus disease 2019: What we know? J Med Virol. 2020;92(7):719-25. https://doi.org/10.1002/jmv. 25766.

10. Hoffman M, Kleine-Weber H, Schroder S, Kruger N, Herrler T, Erichsen S. SARS-CoV-2 Cell entry depends on ACE2 and TMPRSS2 and is blocked by a clinically proven protease inhibitor. Cell. 2020;181:271-80. https://doi.org/10.1016/j.cell.2020. 02.052 .

11. Jung K, Gurnani A, Renukaradhya GJ, Saif LJ. Nitric oxide is elicited and inhibits viral replication in pigs infected with porcine respiratory coronavirus but not porcine reproductive and respiratory syndrome virus. Vet Immunol Immunopathol. 2010;136:335-9. https://doi.org/10.1016/j.vetimm.2010.03.022.

12. Lundberg JO. Nitric oxide and the paranasal sinuses. Anat Rec. 2008;291:1479-84. https://doi.org/10.1002/ar.20782.

13. Lundberg JO, Carlstrom M, Weitzberg E. Metabolic effects of dietary nitrate in health and disease. Cell Metab. 2018;28:9-22. https://doi.org/10.1016/j.cmet.2018.06.007.

14. Lundberg JO, Weitzberg E, Gladwin MT. The nitrate-nitrite-nitric oxide pathway in physiology and therapeutics. Nat Rev Drug Discov. 2008;7:156-67. https://doi.org/10.1038/nrd2466.

15. Martel J, Ko YF, Young JD, Ojcius DM. Could nasal nitric oxide help to mitigate the severity of COVID-19? Microbes Infect. 2020;22(4-5):168-71. https://doi.org/10.1016/j.micinf.2020.05. 002 .

16. Mondal S, Quintili AL, Karamchandani K, Bose S. Thromboembolic disease in COVID-19 patients: A brief narrative review. J Intensive Care. 2020;8:70. https://doi.org/10.1186/ s40560-020-00483-y.

17. Nagaki M, Shimura MN, Irokawa T, Sasaki T, Shirato K. Nitric oxide regulation of glycoconjugate secretion from feline and human airways in vitro. Respir Physiol. 1995;102:89-95. https:// doi.org/10.1016/0034-5687(95)00042-C.
18. Pascarella G, Strumia A, Piliego C, et al. COVID-19 diagnosis and management: a comprehensive review. J Intern Med 2020. https://doi.org/10.1111/joim.13091.

19. Pope M, Marsden PA, Cole E, Sloan S, Fung LS, Ning Q, Ding JW, Leibowitz JL, Phillips MJ, Levy GA. Resistance to murine hepatitis virus strain 3 is dependent on production of nitric oxide. J Virol 1998;72:7084-90. https://doi.org/10.1128/JVI.72.9.70847090.1998.

20. Ritz T, Trueba AF, Vogel PD, Auchus RJ, Rosenfield D. Exhaled nitric oxide and vascular endothelial growth factor as predictors of cold symptoms after stress. Biol Psychol. 2018;132:116-24. https://doi.org/10.1016/j.biopsycho.2017.11.006.

21. Runer T, Cervin A, Lindberg S, Uddman R. Nitric oxide is a regulator of mucociliary activity in the upper respiratory tract. Otolaryngol Head Neck Surg. 1998;119:278-87

22. Saura M, Zaragoza C, McMillan A, Quick RA, Hohenadl C, Lowenstein JM. An antiviral mechanism of nitric oxide: inhibition of a viral protease. Immunity. 1999;10:21-8. https://doi.org/ 10.1016/S1074-7613(00)80003-5.

23. Tousoulis D, Kampoli A-M, Tentolouris C, Papageorgiou N, Stefanadis C. The role of nitric oxide on endothelial function. Curr Vasc Pharmacol. 2012;10:4-18. https://doi.org/10.2174/ 157016112798829760.

24. Wu D, Wu T, Liu Q, Yang Z. The SARS-CoV-2 outbreak: What we know. Int J Infect Dis. 2020;94:44-8. https://doi.org/10.1016/ j.ijid.2020.03.004

25. Xu Z, Shi L, Wang Y, et al. Pathological findings of COVID-19 associated with acute respiratory distress syndrome. Lancet Resp Med. 2020;8:420-2. https://doi.org/10.1016/S22132600(20)30076-X.

26. Xu W, Zheng S, Dweik RA, Erzurum SC. Role of epithelial nitric oxide in airway viral infection. Free Radic Biol Med. 2006;41:19-28. https://doi.org/10.1016/j.freeradbiomed.2006.01. 037.

27. Yang Y, Peng F, Wang R al. The deadly coronaviruses: The 2003 SARS pandemic and the 2020 novel coronavirus epidemic in China. J Autoimmun 2003;2020:102434; https://doi.org/10.1016/ j.jaut.2020.102434.

28. Zhang T, He Y, Xu W, Ma A, Yang Y, Xu K-F. Clinical trials for the treatment of Coronavirus disease 2019 (COVID-19): a rapid response to urgent need. Sci China Life Sci. 2020;63:774-6. https://doi.org/10.1007/s11427-020-1660-2.

\section{Publisher's Note}

Springer Nature remains neutral with regard to jurisdictional claims in published maps and institutional affiliations. 